IZA DP No. 627

\title{
Cyclical Fluctuations in Workplace Accidents
}

\author{
J an Boone \\ J an C. van Ours \\ November 2002
}




\title{
Cyclical Fluctuations in Workplace Accidents
}

\author{
Jan Boone \\ Tilburg University, CentER and CEPR \\ Jan C. van Ours \\ Tilburg University, CentER, Institute for Labour Studies (OSA), \\ CEPR and IZA Bonn
}

\author{
Discussion Paper No. 627 \\ November 2002
}

\author{
IZA \\ P.O. Box 7240 \\ D-53072 Bonn \\ Germany \\ Tel.: +49-228-3894-0 \\ Fax: +49-228-3894-210 \\ Email: iza@iza.org
}

This Discussion Paper is issued within the framework of IZA's research area The Future of Labor. Any opinions expressed here are those of the author(s) and not those of the institute. Research disseminated by IZA may include views on policy, but the institute itself takes no institutional policy positions.

The Institute for the Study of Labor (IZA) in Bonn is a local and virtual international research center and a place of communication between science, politics and business. IZA is an independent, nonprofit limited liability company (Gesellschaft mit beschränkter Haftung) supported by the Deutsche Post AG. The center is associated with the University of Bonn and offers a stimulating research environment through its research networks, research support, and visitors and doctoral programs. IZA engages in (i) original and internationally competitive research in all fields of labor economics, (ii) development of policy concepts, and (iii) dissemination of research results and concepts to the interested public. The current research program deals with (1) mobility and flexibility of labor, (2) internationalization of labor markets, (3) welfare state and labor market, (4) labor markets in transition countries, (5) the future of labor, (6) evaluation of labor market policies and projects and (7) general labor economics.

IZA Discussion Papers often represent preliminary work and are circulated to encourage discussion. Citation of such a paper should account for its provisional character. A revised version may be available on the IZA website (www.iza.org) or directly from the author. 
IZA Discussion Paper No. 627

November 2002

\section{ABSTRACT}

\section{Cyclical Fluctuations in Workplace Accidents*}

This paper presents a theory and an empirical investigation on cyclical fluctuations in workplace accidents. The theory is based on the idea that reporting an accident dents the reputation of a worker and raises the probability that he is fired. Therefore a country with a high or an increasing unemployment rate has a low (reported) workplace accident rate. The empirical investigation concerns workplace accidents in OECD countries. The analysis confirms that workplace accident rates are inversely related to both the level of unemployment and the change in unemployment. Furthermore, fatal accident rated do not fluctuate over the cycle. We conclude that our empirical analysis is in line with our theory: cyclical fluctuations in workplace accidents have to do with reporting behavior of workers and not with changes in workplace safety.

JEL Classification: $\quad$ I31, J28

Keywords: workplace accidents, unemployment

Corresponding author:

Jan C. van Ours

Department of Economics and CentER

Tilburg University

P.O. Box 90153

5000 LE Tilburg

The Netherlands

Tel.: +31-13-4662316

Fax: +31-13-4663042

Email: vanours@kub.nl

\footnotetext{
* The authors are grateful to Joost Lebens for excellent research assistance and to Maria Guadalupe and seminar participants at LBS for comments on a previous version of the paper. The first author would like to thank NOW, KNAW and VSNU for financial support through a Vernieuwingsimpuls grant.
} 


\section{Introduction}

According to the European Statistics on Accidents at Work an accident at work is defined as a "discrete occurrence in the course of work, which leads to physical or mental harm." ${ }^{1}$ Workplace accidents are a common phenomenon. In the EU during 1998 there were 4.7 million occupational accidents leading to more than 3 days' absence from work, which is equivalent to an accident rate - i.e. the probability that a worker is involved in a workplace accident - of $4.1 \%$. The total number of accidents, including those which did not involve absence from work amounted to 7.4 million, equivalent to an accident rate of $6.4 \%$. A fatal accident is defined as an accidents, which leads to the death of a victim within one year (after the day) of the accident. The incidence of accident-related deaths was 5.0 per 100,000 workers. Around 150 million working days are lost, which is about $0.5 \%$ of total working time. ${ }^{2}$

The rate of workplace accidents differs between countries and changes over time. Cross-country differences in workplace accident rates are mainly related to differences in definitions and measurement. The changes over time are more difficult to explain. Some countries have a downward trend in their accident rates because of safer work conditions or changes in industrial structure. However a decline in accident rate is not present in every country. Furthermore, as we will show in more detail below, workplace accident rates are procyclical, which could indicate that on average work is more dangerous in booms than it is in slumps. If so, this would be in line with evidence presented by Ruhm (2000) indicating that booms are unhealthy. Ruhm finds a strong inverse relationship between macroeconomic conditions and mortality, which he attributes to hazardous working conditions, the physical exertion of employment, and job-related stress when job hours are extended during short-lasting economic expansions. ${ }^{3}$ This explanation for the procyclicality of workplace accidents has to do with working conditions. In booms the effort level of workers is higher and more inexperienced workers

\footnotetext{
${ }^{1}$ This includes cases of acute poisoning and willful acts of other persons but excludes selfinflicted injuries and commuting accidents. "In the course of work" means whilst engaged in an occupational activity or during the time spent at work. This includes cases of road traffic accidents in the course of work.

${ }^{2}$ Information from the European Agency for Safety and Health at Work - Facts 19.

${ }^{3}$ Ruhm (2000) investigates the relationship between economic conditions and health, using U.S. state specific data. Other possible reasons for the inverse relationship mentioned are that higher employment rates are associated with increases in smoking and obesity, reduced physical activity, and worse diets. Also, the higher incomes associated with good economic times may lead to increases in some risky activities. Ruhm (2001) finds that there is countercyclical variation in physical health while there is some evidence that mental health is procyclical.
} 
are hired. The idea is that when employers require high effort levels from their workers, these workers become less careful. Hence the number of workplace accidents increases. When workers exert less effort, they can take more care and are therefore involved in less accidents. If effort is procyclical (employers require higher effort levels in booms) so are workplace accidents. Consequently, workplace accidents are negatively correlated with unemployment. Also in booms more workers are hired than in slumps. If newly hired workers are less experienced and are therefore more likely to be involved in workplace accidents there are more accidents in a boom.

An alternative explanation for the cyclicality in workplace accidents is related to the well-known procyclical variation in workers' absenteeism. If unemployment is high, workers fear to loose their job, so conditional on a specific state of their health they are less inclined to stay away from work. If unemployment is low, employers will be more reluctant to fire a worker even in case of frequent absenteeism. So, absence-prone workers are more likely to be dismissed in an economic downturn (Leigh (1985)). In terms of workplace accidents the idea is that workers are reluctant to report these accidents when they fear that employers will hold this against them. For an individual worker the probability to be dismissed is equal to the product of the average probability to be dismissed and the ratio of individual specific probability and average probability. The first probability depends on the economic position of the firm, which in itself will generally depend on the macroeconomic situation, i.e. the cycle. The second ratio depends on the behavior of the individual compared to the behavior of his or her colleagues and may be related to a workplace accident. Therefore, workers may be reluctant to report a workplace accident. The reporting rate of workplace accidents may be influenced by the perceived likelihood of being dismissed because of the accident and by the consequences of being unemployed conditional on a particular dismissal probability. The two determinants of the reporting rate have different implications for the cyclical behavior. The first determinant implies that the reporting rate is low if unemployment is increasing, while the second determinant implies that the reporting rate is low if unemployment is high.

This paper focuses on the question whether high workplace accidents rates in a boom are a true phenomenon related to stress or inexperienced workers and thus an indication of workers' health being harmed in prosperous times or whether alternatively high workplace accidents rates in a boom are a spurious phenomenon caused by changes in workers reporting behavior. The two explanations for the cyclicality of workplace accidents are tested empirically. Part of the evidence presented uses the distinction between non-fatal and fatal accidents (see the ap- 
pendix for more details). The 'working conditions' explanation predicts that the level of unemployment is negatively related to workplace accidents. Furthermore, it predicts that working hours have a positive effect on workplace accidents because working longer increases the probability of an accident. Also, the change in employment is positively related to workplace accidents since an increase in employment coincides with a lot of new hirings while a decrease in employment is related to few new hirings. If working conditions are the driving force not only the non-fatal accidents but also the fatal accidents will exhibit cyclicality. The 'reporting' explanation predicts that both the level and the change in unemployment are negatively related to workplace accidents. Furthermore, the cyclicality should be found only in the case of non-fatal accidents and should not be found in the case of fatal accidents because there is no reporting decision in the latter case.

In our empirical analysis it appears that both the level and the change in unemployment are negatively related to workplace accidents while working hours and the change in employment have no effect on workplace accidents. Furthermore, cyclicality is found only for non-fatal workplace accidents. From this evidence we conclude that the procyclical behavior of workplace accidents is most likely related to reporting rates and not to actual fluctuations in accidents. From a policy perspective this result implies that when in cyclical upturns the workplace accidents rate goes up there is no urgent need to start worrying about workplace safety.

The paper is set up as follows. In Section 2 we set the stage by giving an overview of previous studies on absenteeism and workplace accidents. In Section 3 we present a theoretical model that explains the cyclicality in reported workplace accidents showing that both the level of unemployment and the change in unemployment affect the reported workplace accidents. Section 4 describes the data on workplace accidents from 17 OECD countries, discusses the statistical model and presents estimation results. Section 5 concludes.

\section{Previous studies}

There are several studies that investigate the cyclicality of workplace absenteeism. According to Barmby et al. (1994) the effect of absence behavior on the probability of being fired may act as a worker discipline device. Brown and Sessions (1996) distinguishes between absence that occurs for valid (i.e. 'sickness') and invalid (i.e. 'shirking') reasons. According to them little attention has been paid in the economic literature to either the causes or the effects of absenteeism. They ana- 
lyze absence within the framework of the static neoclassical labor supply model in which a worker has an incentive to absent himself if the level of contractual hours specified by the employer exceeds his desired hours. According to Johansson and Palme (1996) when unemployment increases, shirking or absenteeism decreases. They use a 1981 Swedish micro dataset to investigate the relationship between work absence and county-specific annual average unemployment rates. They find a negative relationship. Johansson and Palme (2002) presents an analysis of panel data showing a declining work absence of Swedish blue-collar workers during a period in which there was a major reform in the income replacement program for short-term sickness and income taxes. It turns out that the cost of being absent significantly affects work absence behavior. The increased cost, rather than the higher unemployment rate, caused the decrease in the work absence rate. According to Arai and Thoursie (2001) procyclical absenteeism might be due to higher sick-rates of marginal workers, or a consequence of procyclical sick-report incentives. They use Swedish data for 14 industries in 3 regions to investigate the correlation between sick rates and the share of temporary contracts. A positive correlation would imply a selection effect, a negative relation would imply a worker incentive effect. The results show that the sick-rate and the share of temporary contracts are negatively and significantly correlated. Finally, Askildsen et al. (2002) use a panel of Norwegian register data over the period 1990-95 to distinguish between two alternative explanations for the cyclicality in absence behavior: disciplining effects of unemployment and changes in the composition of the labor force (when labor is scarce marginal workers who are more prone to be absent are offered jobs). They find that county-specific unemployment rates are negatively related to both the probability of having a sickness spell in a given year and for the duration of absence. They find that this also holds for a subsample of stable workers (those who are in the labor force for a long period). From this they conclude that the selection effect is not causing the cyclical behavior. So, although as far as absenteeism is concerned incentives and composition effects are two competing explanations for cyclical fluctuations the incentive effect seems to be the dominant one.

There are also a number of studies investigating workplace accidents. Kossoris (1938) is a very early reference to the pro-cyclical pattern in accident rates. Schuster and Rhodes (1985) conclude that there is little evidence of overtime hours being systematically related to injury rate risk. Kniesner and Leeth (1989) presents a numerical simulation, based on data from the early 1970s, to investigate the economic links between labor market outcomes and the workers' compensation insurance system. Their results suggest that the observed positive associ- 
ation between work-related injuries and benefits across states reflects incentives for workers to report injuries rather than it reflects an economic incentive for employers to invest less in workplace safety. Meyer et al. (1995) uses a "natural experiment" in two American states (Kentucky and Michigan) to compare individuals injured before and after increases in the maximum benefit amount. They find that time out of work increased for those eligible for the higher benefits and remained unchanged for those whose benefits were constant. Hokkanen (1998) uses the frequency of industrial injury rates as an indicator of unobservable labor effort. This idea comes from Shea (1990) who suggests that accidents only occur in the workplace if labor really works. Therefore in recessions when workers perform less tasks per hour or are assigned to non-production activities (maintenance, repairing) the number of accidents per hour should fall. If firms require more effort from labor in booms and less in recessions, then labor effort will be pro-cyclical and the injury rate will be positively correlated with aggregate fluctuations in the economy. Hokkanen does not study injury rates directly but concludes that the injury rate variable that is used as a proxy for unobserved labor effort is significantly related to output in the production function regression, "which is to be expected if true labor effort is pro-cyclical". Shea (1990) suggests that variables such as overtime, hiring and firing rates, the share of nonproduction workers, and the investment-to-capital ratio may affect accident rates over the business cycle. What matters for the development of the injury rates are the flows in and out of the labor force, i.e. the hiring and firing rates. Fairris (1998) shows that in US manufacturing injury rates are procyclical. Also, in the 1940s and 1950s injury rates in U.S. manufacturing declined whereas in the 1960s these rates increased. He states that reduced workplace safety due to changes in the institutional arrangements of shopfloor governance is likely to be responsible for this.

\section{$3 \quad$ Workplace accidents - theory}

This section introduces a model to formalize the relation between cyclical variations in output and workplace accidents. The idea is that reporting an accident dents a worker's reputation and raises the probability that he will be fired. This is especially disadvantageous for the worker if the value of being unemployed is low or decreasing. Hence in such circumstances one expects fewer accidents to be reported. The value of being unemployed varies with the business cycle. In the empirical analysis we use unemployment as an indicator of the cycle. Hence the model relates unemployment to workplace accidents in the following two ways. 
First, comparing two countries where one has higher unemployment than the other, we show that, ceteris paribus, the country with the higher unemployment rate has a smaller number of reported workplace accidents. Second, following two countries over time, if unemployment increases faster in one country than in the other we show that, ceteris paribus, the number of reported workplace accidents is smaller in the country with the biggest rise in unemployment.

The idea that reporting an accident may raise the probability of being fired is similar to an idea in Barmby et. al. (1994). They introduce an efficiency wage model of absenteeism. Workers shirk in this model by overstating their 'level of sickness' in order to stay at home. To discipline workers, the firm invests in a monitoring technology to verify workers' health status. If an absent worker is found to be fit enough to work, this is seen as shirking and the worker is fired. A difference between absenteeism and our model of accidents is the following. Absenteeism is observable, while the motivation for being absent (sickness or laziness) is not (directly observable). In our model, an (non-fatal) accident is not observable by the firm unless it is reported by the worker. Once the accident is reported, the firm can determine the damage caused by the accident and compensate the worker accordingly.

Consider the following model of workplace accidents. Each worker has an exogenous probability $\phi$ of experiencing a (non-fatal) workplace accident. The damage (in terms of utility) of the accident to the worker is denoted by $\alpha \geq 0$, which is a random variable with density function $f($.$) and distribution function$ $F($.$) . After the accident has happened, a worker decides whether to report it or$ not. If he reports the accident, the firm pays him a compensation $\gamma(\alpha)$ which depends on the damage the worker incurred. It seems reasonable to assume that $\gamma^{\prime}(\alpha) \geq 0$. However, reporting also has a stigma effect: the firm concludes that workers who report an accident may be more accident prone than workers who have never reported an accident. Hence, if the firm has to fire some workers (say, in a downturn) workers who have reported an accident are more likely to be fired than workers who never reported an accident.

Using a dynamic model of the labour market in the vein of Mortensen and Pissarides (1999), let $V_{E}(t)$ denote the value of having a job at time $t$ while the worker has never reported an accident at its current employer. ${ }^{4}$ We assume that

\footnotetext{
${ }^{4}$ We assume that when a worker is fired and finds a new job, his new employer does not know whether he has reported accidents at his previous employers.
} 
$V_{E}(t)$ is determined by the following Bellman equation

$$
\begin{aligned}
\rho V_{E}(t)= & w+\phi \int_{0}^{+\infty}\left[-\alpha+\max \left\{\gamma(\alpha)+V_{A}(t)-V_{E}(t), 0\right\}\right] f(\alpha) d \alpha \\
& +\delta_{E}\left(V_{u}(t)-V_{E}(t)\right)+\dot{V}_{E}(t)
\end{aligned}
$$

where $\rho$ is the discount rate, $V_{A}(t)$ is the value of employment once a worker has reported an accident, $V_{u}(t)$ is the value of being unemployed and $\delta_{E}$ is the (flow) probability of being fired. Thus, the value of being employed at the firm equals the sum of four terms: the wage $w$ received while being employed, the (flow) probability that an accident happens (see below), the firing probability $\delta_{E}$ and the change in the value of $V_{E}(t)$.

We assume that either the wage is determined by Nash bargaining ${ }^{5}$ or that workers are free to quit the job. Assuming that workers have some bargaining power, both imply that $V_{E}(t)-V_{u}(t)>0$. Below we specify a matching model for unemployment. In that case, the inequality $V_{E}(t)-V_{u}(t)>0$ holds if $w-$ $\phi \int_{0}^{+\infty} \alpha f(\alpha) d \alpha$ exceeds the unemployment benefit level $b$.

We view equation (1) as a differential equation with an exogenous time path for $V_{u}($.$) . The time path for V_{A}($.$) is derived below. The time path for V_{u}($.$) can$ be perfectly predicted by agents ${ }^{6}$ and we assume that $\left|V_{u}().\right|<M$ for some $M>$ 0 . Below we consider a search and matching imperfection in the labor market which implies that $\frac{b}{\rho}<V_{u}(t)<\frac{w+\int_{0}^{+\infty} \gamma(\alpha) f(\alpha) d \alpha}{\rho}$, where $b$ is the unemployment benefit level. Hence, for $M=\frac{w+\int_{0}^{+\infty} \gamma(\alpha) f(\alpha) d \alpha}{\rho}$, we indeed find that $\left|V_{u}(t)\right|<M$ for all $t$.

Next, consider the worker's response after an accident happens. The accident gives him the disutility $\alpha$ of the damage. Then the worker decides whether to report the accident or not. If he does not report the accident, he gets no compensation nor a stigma. If he does report the accident, he gets the compensation $\gamma(\alpha)$ from the firm, but also has the reputation of someone who has reported an accident. That is, his continuation pay off is $V_{A}(t)$ instead of $V_{E}(t)$. Clearly, this reporting decision is only relevant for non-fatal accidents since fatal accidents are always reported.

\footnotetext{
${ }^{5}$ There is an issue here whether the Nash bargained wage is continuously renegotiated in response to, for instance, changes in $V_{u}(t)$ over time. For notational simplicity we assume that $w$ is constant over time, however all results below go through if $w$ would be indexed by $t$ as well.

${ }^{6}$ If this were not the case, the analysis would be done in terms of expected values for unemployment, employment etc. For the problem we are considering, nothing would be gained by working in terms of expected values.
} 
We assume that the Bellman equation for someone who has reported an accident equals

$$
\rho V_{A}(t)=w+\phi \int_{0}^{+\infty}[-\alpha+\gamma(\alpha)] f(\alpha) d \alpha+\delta_{A}\left(V_{u}(t)-V_{A}(t)\right)+\dot{V}_{A}(t)
$$

where $\delta_{A}$ is the probability that a worker who has reported an accident will be fired. As mentioned above, we assume that workers who have reported an accident are more likely to be fired (when the firm has to fire employees) than workers who have reported no accidents. Hence, we assume that $\delta_{A}>\delta_{E}$. We also assume that reporting an accident has no effect on a worker's wage, which would indeed be illegal in most if not all countries in our dataset. Next, we suppose, for simplicity, that reporting more than one accident instead of just one accident has no effect on the probability of being fired. This is just to simplify notation. All the results below go through as long as the probability of being fired $\delta_{A}$ is nondecreasing in the number of accidents reported. Since we assume that $\delta_{A}$ does not further increase by reporting more than one accident, it is optimal for the worker to report each accident after the first one and receive the compensation $\gamma(\alpha)$ from the firm.

Since $V_{u}(t)-V_{E}(t)<0$ and because a worker who has not reported an accident yet can always mimic the behavior of a worker who has already reported an accident, we find that $\delta_{A}>\delta_{E}$ implies $V_{E}(t)>V_{A}(t)$.

It is now straightforward to see that a worker's optimal reporting strategy takes the following form. Report an accident if and only if $\gamma(\alpha)-\left(V_{E}(t)-V_{A}(t)\right) \geq$ 0 . Since by assumption $\gamma^{\prime}(\alpha) \geq 0$, for given $V_{E}(t)-V_{A}(t)$ only accidents $\alpha \geq \bar{\alpha}$ are reported. Hence, conditional on $V_{E}(t)-V_{A}(t)$ the probability that an accident is reported equals $\phi(1-F(\bar{\alpha}))$. Next note that as $V_{E}(t)-V_{A}(t)$ becomes smaller, the loss of reporting an accident becomes smaller, and hence more accidents will be reported.

So the crucial question is how the path of $V_{u}$ (.) affects the difference $V_{E}()-$. $V_{A}($.$) , because that is the channel through which the unemployment rate affects$ the number of accidents reported. Now we solve the differential equations (1) and (2) with an exogenous path for $V_{u}$ (.) not as initial value problems, but as a boundary value problem in the following sense. Suppose that for some $T>0$ it is the case that $V_{u}(t)=\bar{V}_{u}$ for all $t \geq T$. Then we want the solutions $V_{E}(t)$ and $V_{A}(t)$ to converge to the solutions of (1) and (2) with $\dot{V}_{A}(t)=\dot{V}_{E}(t)=0$. So, for instance, $V_{A}(t)$ should converge to $V_{A}=\frac{w+\phi \int_{0}^{+\infty}[-\alpha+\gamma(\alpha)] f(\alpha) d \alpha}{\rho+\delta_{a}}+\frac{\delta_{A}}{\rho+\delta_{A}} \bar{V}_{u}$. This is the solution that follows from perfect foresight.

Before specifying how $V_{u}(t)$ is determined, we can derive the effect of $V_{u}(t)$ on the number of reported accidents. This we do in two different ways. First, we 
look at pure level effects. Second, we consider two different time paths for $V_{u}($. but control for level effects so as to focus on the effect of a changing derivative $\dot{V}_{u}(t)$. The pure level effect can be characterized as follows. All results are proved in appendix 2 .

Proposition 1 Consider a time path for the value of being unemployed $V_{u}(t)$ and an alternative time path $V_{u}(t)+\varepsilon$. Then $\varepsilon>0$ implies that the number of accidents reported under the alternative time path exceeds the number of accidents reported under the original time path.

This is a pure level effect, since for each $t$ the two time paths for $V_{u}($.$) are$ exactly the same (same time derivatives etc.) up to a shift in the level of $V_{u}$. The intuition for the result is that under the alternative time path (with $\varepsilon>0$ ) becoming unemployed is not as bad as under the original time path. Hence reporting an accident (which makes a worker unemployed sooner, in expected terms) has not such negative consequences under the alternative time path than under the original. Hence, one would expect to see more accidents reported under the alternative time path.

In order to compare the number of accidents reported for two different time paths of $V_{u}($.$) controlling for the level effect, we need to introduce some notation$ first. Given a real valued function $g($.$) of time t$ with $|g()|<$.$M for some M>0$, we define the function $\bar{g}^{\psi}(t)$ for $\psi>0$ as

$$
\bar{g}^{\psi}(t)=\psi \int_{t}^{+\infty} e^{-\psi(s-t)} g(s) d s
$$

In words, $\bar{g}^{\psi}(t)$ is a weighted average of all future values of $g($.$) starting from time$ $t$. Note that $\psi \int_{t}^{+\infty} e^{-\psi(s-t)} d s=1$ and hence equation (3) is indeed a weighted average. ${ }^{7}$ We see $\bar{g}^{\psi}(t)$ as a summary of the long run behavior of the function $g($.$) as of time t$. Now we can formulate how we compare two different time paths for $V_{u}$ controlling for level effects.

Proposition 2 Consider two time paths $V_{u 1}(t)$ and $V_{u 2}(t)$ which satisfy

$$
\begin{aligned}
V_{u 1}(0) & =V_{u 2}(0) \\
\bar{V}_{u 1}^{\rho+\delta_{A}}(0) & =\bar{V}_{u 2}^{\rho+\delta_{A}}(0)
\end{aligned}
$$

there exists a value of $T>0$ such that

$$
V_{u 1}(t)=V_{u 2}(t) \text { for all } t \geq T
$$

\footnotetext{
${ }^{7}$ In fact, the weights follow an exponential distribution. Also, note that the definition of $\bar{g}^{\psi}$ is closely related to a Laplace transformation.
} 
Then $\dot{V}_{u 1}(0)>\dot{V}_{u 2}(0)$ implies that the number of accidents reported at time $t=0$ is smaller under time path $V_{u 2}$ than under $V_{u 1}$.

The proposition considers two time paths where the first is either more steeply upward sloping than the second, or the first is upward sloping while the second is downward sloping, or the second is more steeply downward sloping than the first at $t=0$. We are interested in the effect of this inequality $\dot{V}_{u 1}(0)>\dot{V}_{u 2}(0)$ on the number of reported accidents. Figure 1 illustrates a possible time path for $V_{u 2}(t)-V_{u 1}(t)$. The three conditions in the proposition take out the level effects. In particular, the first condition makes sure that both paths start at the same value, $V_{u 1}(0)=V_{u 2}(0)$. So there is no level effect to start with. The third condition makes sure that the two paths coincide from some time $T>0$ onward, hence there are no long term level effects either.

The second condition is slightly more subtle. It is relatively straightforward to see that the first and the third condition are not sufficient to eliminate level effects. For instance, a time path $V_{u 2}(t)$ with $V_{u 1}(0)=V_{u 2}(0)$ but which otherwise lies everywhere below $V_{u 1}(t)$ for $t \in\langle 0, T\rangle$ and coincides again with $V_{u 1}($.$) for all$ $t \geq T$ satisfies the two conditions. Yet, there is still a level effect since the second time path is unambiguously worse for an agent than the first. To avoid this latter effect, it must be the case that the initial negative difference $V_{u 2}(t)-V_{u 1}(t)$ is compensated later on by a positive difference, as illustrated by Figure 1 . This is exactly what the second condition, $\bar{V}_{u 1}^{\rho+\delta_{A}}(0)=\bar{V}_{u 2}^{\rho+\delta_{A}}(0)$, ensures. It says that the long run behavior of the two time paths, as seen from time $t=0$, is the same. One time path does not yield a consistently higher or lower value than the other path. In particular, this condition implies that the two time paths for $V_{u}$ have the same value for $V_{A}$ at time $t=0$ (for details see the appendix).

The result now says that comparing two time paths for $V_{u}$, where all level effects have been removed, and where it is the case that $\dot{V}_{u 1}(0)>\dot{V}_{u 2}(0)$ we find that the number of accidents reported at time $t=0$ is higher under the first time path than under the second. The intuition is the following. The difference between the expected discounted value of being employed without having reported an accident, $V_{E}$, and the discounted value while having reported an accident, $V_{A}$, is determined by the expected duration until unemployment. Once a worker has reported an accident, he is expected to become unemployed sooner (since $\delta_{A}>\delta_{E}$ ) so a reduction in the value of becoming unemployed (while controlling for long run level effects) at $t=0$ has a bigger negative effect on $V_{A}$ then on $V_{E}$. Hence, $V_{E}(0)-V_{A}(0)$ increases as $V_{u}$ falls faster at $t=0$ and fewer accidents are reported.

Up until now, we have analyzed the effects of $V_{u}$ on the reported number of 
accidents. However, in the empirical analysis we look at the effects of the business cycle, proxied by unemployment rate $u($.$) , on the number of reported accidents.$ The remainder of this section links the development of $u($.$) to the development of$ $V_{u}$ (.). In order to do this, we work with a search and matching model in the labor market. In particular, we assume that the development of $V_{u}$ (.) is determined by the following differential equation

$$
\rho V_{u}(t)=b+q(u(t))\left[V_{E}(t)-V_{u}(t)\right]+\dot{V}_{u}(t)
$$

where $b$ is the unemployment benefit level and $q($.$) denotes the probability that$ an unemployed worker is matched with job. We assume that $b<w+\phi \int_{0}^{+\infty}[-\alpha+$ $\gamma(a)] f(\alpha) d \alpha$ which implies that a worker is better off having a job than remaining unemployed. Since we assume that a new employer does not know whether the worker has reported an accident in his previous job, the value of a new job is $V_{E}$ irrespective of the history of the worker. We view this as a differential equation determining $V_{u}(t)$ as a function of the exogenous time path for unemployment $u(t)$, where $V_{E}(t)$ is determined by equation (1).

We assume that the probability of getting a job is decreasing in the unemployment level $u(t)$, that is $\frac{d q(u(t))}{d u(t)}<0$ for all $t$. This implies that the value of being unemployed $V_{u}$ falls with the unemployment level, since a higher unemployment level increases the expected duration of the unemployment spell. The way we think of the function $q($.$) is as a matching probability, where the number of$ matches each period equals $m(u(t), v(t))$ for some matching function $m(.,$.$) and$ where $v(t)$ denotes the number of vacancies posted at time $t$. Hence the probability of being matched at time $t$ for an unemployed worker equals $\frac{m(u(t), v(t))}{u(t)}$. We do not model the number of vacancies $v(t)$ but assume that a Beveridge curve exists (see for example Nickell et al. (2001)). That is, $v(t)$ is negatively correlated with $u(t)$. Thus we write $q(u(t))=\frac{m(u(t), v(u(t)))}{u(t)}$, with $q^{\prime}(u)<0$. Below we consider different time paths for $u($.$) , keeping the function q($.$) the same.$

Since $V_{u}(t)$ is decreasing in $u(t)$, we can formulate the results in the propositions above as follows.

Corollary 3 Consider two steady state unemployment levels $u$ and $u+\varepsilon$. Then $\varepsilon>0$ implies that the number of accidents reported in the alternative steady state is lower than the number of accidents reported in the original steady state. Consider two time paths $u_{1}(t)$ and $u_{2}(t)$ with

$$
\begin{aligned}
& u_{1}(0)=u_{2}(0) \\
& u_{1}(t)=u_{2}(t) \text { for all } t \geq T
\end{aligned}
$$


for some $T>0$. These time paths induce time paths for $V_{u 1}$ and $V_{u 2}$ resp. that satisfy

$$
\begin{aligned}
V_{u_{1}}(0) & =V_{u_{2}}(0) \\
\bar{V}_{u 1}^{\rho+\delta_{a}}(0) & =\bar{V}_{u 2}^{\rho+\delta_{a}}(0)
\end{aligned}
$$

Then $\dot{u}_{1}(0)<\dot{u}_{2}(0)$ implies that the number of reported accidents at $t=0$ is lower under time path $u_{2}($.$) than under u_{1}($.$) .$

Hence we see that a higher unemployment level leads to fewer reported accidents. When considering the effect of a change in unemployment level, we need to correct again for level effects (as in proposition 2). This takes the form here that at $t=0$ the unemployment level is the same for both series. Further, from some future date $T>0$ onwards, the unemployment levels coincide for both series. Yet, this is not enough to remove level effects, as it does not exclude the case where $u_{1}(t)<u_{2}(t)$ for all $t \in\langle 0, T\rangle$ and path 2 is unambiguously worse for a worker than path 1 . The two conditions on the value of being unemployed removes these level effects. If unemployment rises faster at $t=0$ under time path 2 than under 1, then the value of being unemployed initially falls faster under time path 2 than under $1\left(\dot{V}_{u 2}(0)<\dot{V}_{u 1}(0)\right)$ since it is relatively harder to find a job. Proposition 2 then implies that fewer accidents are reported under time path 2 than under 1. Summarizing, we find a smaller number of accidents reported when unemployment rises.

\section{Workplace accidents across the OECD}

\subsection{Data}

There are clear differences in the ways in which countries define and register workplace accidents. Differences refer for example to the minimum number of working days lost to the accidents, the severeness of the accidents, whether or not commuting accidents are included. ${ }^{8}$ To give some examples for the year 1995: in Canada there were about 410,000 workplace accidents of which 750 were fatal, France had 670,000 workplace accidents of which 700 were fatal, Italy

\footnotetext{
${ }^{8}$ According to the European Agency for Safety and Health at Work depending on the reporting procedure (insurance or non-insurance based systems) the reporting levels for accidents at work differ. In general, the reporting levels are very high in the insurance based systems and considered to be about 100\%. The non-insurance based system has only a medium reporting level usually ranging from 30 to $50 \%$, on average, for all branches of economic activity taken together.
} 
had 660,000 workplace accidents of which 1150 were fatal, Spain had 600,000 workplace accidents of with 1000 were fatal, UK had 150,000 workplace accidents of which 230 were fatal and the US had 2.8 million workplace accidents of which 6300 were fatal. The appendix provides more details about the data.

Figure 2 shows the evolution of (non-fatal) workplace accident rates and unemployment rates for the 17 OECD countries in our sample. As shown in many but not all countries there is a downward trend in workplace accident rates. Countries where there is no clear downward trend are Denmark, Ireland and Spain. Nevertheless, for some countries it is clear that there is an inverse relationship between workplace accidents and unemployment. For example the increase in unemployment rate in the early 1990s in Canada, Finland and Sweden is accompanied by a major drop in the workplace accident rate. In Ireland the major drop in unemployment rate since the mid 1990s is accompanied by a strong increase in the workplace accident rate. In countries like Denmark, France, Italy, Portugal and Spain there are several upturns and downturns in the unemployment rates where the accident rates show mirror images. For the US this is also the case until the early 1990s. After that both the unemployment rate and the workplace accident rate have gone down.

Table 1 gives a summary presentation of workplace accidents rates - both fatal and non-fatal - across the OECD. As is obvious there is a big range in accident rates, from as low as $0.4 \%$ in Ireland to $8.1 \%$ in Belgium and $9.6 \%$ in Luxembourg. These differences partly have to do with the definition of workplace accidents. In Ireland and the UK for example workplace accidents refer to incapacity of the worker of 4 workdays or more. In Austria and Portugal for example workplace accidents include non-fatal cases without lost workdays. Also for fatal workplace accidents there is a wide difference between countries from a low $0.001 \%$ in the Netherlands to a high $0.011 \%$ in Luxembourg. Over the same calendar time period the unemployment rate varied from $1.7 \%$ in Luxembourg to $18.9 \%$ in Spain. Since the differences in level of workplace accidents may have more to do with differences in data collection than they have to do with real differences it is especially the within country correlation between accident rates and unemployment rates which is interesting to investigate. The fourth column of Table 1 shows that in most countries there is a significant negative correlation between both rates. Only for Denmark, the UK and the US there is a positive but insignificant correlation between both rates. The last column of Table 1 shows the correlation between the fatal accident rates and the unemployment rates for each of the countries involved. Here too there is frequently a significant negative correlation. Of course both the correlation between unemployment and 
(non-fatal) workplace accidents and the correlation between unemployment and fatal workplace accidents may be based on trendlike developments, with unemployment going up in many countries and workplace accidents going down. In order to accounts for these trends we have to perform a multivariate analysis, which is presented in the next section.

\subsection{Parameter estimates}

Our empirical analysis is based on the relationship between reported workplace accidents and unemployment rates, which we derived in the theoretical section. As discussed in the previous section countries differ in the way they register and collect data on workplace accidents. This means that fixed differences between countries in workplace accidents rates may occur. ${ }^{9}$ It may also be the case that calendar year effects that account for joint influences over time are relevant. And, it may be that there are country-specific time trends that influence the evolution of workplace accidents. These country-specific time trends could reflect working conditions that gradually improve or deteriorate, changes in the industrial structure et cetera. Therefore, we add fixed effects for countries and also calendar years and country specific time trends to the relationship:

$$
\ln \left(a_{i, t}\right)=\beta_{0 i}+\beta_{0 t}+\beta_{1 i} \tau+\beta_{2} \ln \left(u_{i, t}\right)+\varepsilon_{i, t}
$$

where $a$ is the (non fatal) workplace accident rate, $\tau$ is a time trend, $u$ is the unemployment rate, $i$ is a subscript for country, $t$ is the subscript for time and $\varepsilon_{i, t}$ are the error terms. When estimating the parameters of this equation we also added some country-specific dummies to account for breaks in series (see the appendix for details). To account for possible heteroskedasticity we calculated robust standard errors.

The estimation results are shown in Table 2. The upper part of this table concerns the estimation results when we take all information into account and use 356 datapoints for 17 countries. We show parameter estimates of $\beta_{2}$ with and without country-specific time trends. The first column shows that the elasticity of workplace accidents with respect to unemployment equals - 0.11 . This elasticity goes down to -0.16 if country-specific time trends are included. It is obvious that

\footnotetext{
${ }^{9}$ The structure of the workforce may influence the level of the workplace accident rate. In 1998 workers in the EU employed for less than two years were 1.2 to 1.3 times more likely to have an accidents than the average worker, irrespective of whether they had a temporary or permanent contract. Furthermore, the risk of an accidents for people aged between 18 and 24 was 1.4 times the average. Also, there are big differences between industries. In agriculture, hunting and fishing the accident rate was $6.8 \%$, in construction $8.3 \%$.
} 
the unemployment rate has a significant negative effect on non-fatal accidents. For fatal accidents we estimate similar equations as (1). The third column shows that also fatal workplace accidents seem to be influenced by the unemployment rate. However, if we introduce country-specific time trends the elasticity is not different from zero at conventional levels of significance.

The middle part of Table 2 shows the estimation results if we reduce the sample to EU-countries, in which case we have 301 datapoints for 14 countries. As shown the parameter estimates are not much affected by this reduction. The lower part of Table 2 shows the estimation results if we use a balanced sample for the period 1980-86, in which case we have 204 datapoints for 12 countries (11 EU-countries and the US). Again, the parameter estimates do not change a lot. It is clear that the unemployment rate has a significantly negative effect on the non-fatal accidents rate while it does not affect the fatal accident rate.

The lower part of Table 2 also contains sensitivity analyses, where we first introduce the hours actually worked per person employed as potentially explanatory variable.

$$
\ln \left(a_{i, t}\right)=\beta_{0 i}+\beta_{0 t}+\beta_{1 i} \tau+\beta_{2} \ln \left(u_{i, t}\right)+\beta_{3} \ln \left(h_{i, t}\right)+v_{i, t}
$$

where $h$ is the hours actually work per person employed and $v_{i, t}$ are the error terms. As shown the estimation results hardly change. In the regressions with the non-fatal accident rate as dependent variable the coefficient on working hours is negative and highly insignificant. In the regressions with the fatal accident rate as dependent variable the coefficient on working hours is positive though not significantly different from zero. Apparently the number of working hours neither affect non-fatal workplace accidents nor fatal workplace accidents.

Then we subsequently add the change in the unemployment rate and the change in employment as potential explanatory variables:

$$
\ln \left(a_{i, t}\right)=\beta_{0 i}+\beta_{0 t}+\beta_{1 i} \tau+\beta_{2} \ln \left(u_{i, t}\right)+\beta_{4} \Delta \ln \left(u_{i, t}\right)+\beta_{5} \Delta \ln \left(e_{i, t}\right)+v_{i, t}
$$

where $e$ is employment, $\Delta$ the indicator for first differences and $v_{i, t}$ are the error terms.

If we introduce the change in unemployment rate as additional explanatory variable the elasticity of non-fatal workplace accidents with respect to unemployment drops a little bit from -0.19 to -0.16 while the change in unemployment also has a significant negative effect on the accident rate. If we add the change in employment rate as explanatory variable we find that this variable has no significant effect on the accident rate while the effects of unemployment and change in unemployment hardly change. The estimates with country-specific time trends are 
very similar. If we introduce the change in unemployment rate as additional explanatory variable the elasticity of fatal workplace accidents is still insignificantly different from zero. The change in unemployment has a significant negative effect but this effects vanishes if we introduce country-specific time trends.

So high unemployment rates and increases in unemployment rates have a significant negative effect on workplace accident rates whereas changes in employment do not affect accident rates. Fatal accident rates are not influenced by labor market conditions at all. From this we conclude that cyclical fluctuations in the non-fatal workplace accident rate are driven by the reporting behavior of the workers and not by changes in workplace safety.

Table 3 shows country-specific estimates of $\beta_{2}$. For each of the 12 countries in the balanced sample $\widehat{\beta}_{2}<0$, although the values range from a high and insignificant -0.10 for Denmark to a low -0.77 for France. Clearly $\beta_{2}$ is heterogenous parameter. Table 4 shows estimation results we impose restrictions on the country-specific parameter estimates of $\beta_{2}$. The first column shows parameter estimates if we estimate $\beta_{2}$ for 3 groups of countries. The largest group has a $\widehat{\beta}_{2}$ of -0.17 , while for the second group $\widehat{\beta}_{2}=-0.70$ and for the third group $\widehat{\beta}_{2}=-0.34$. From a Likelihood Ratio test comparing the restricted estimates with the fully flexible parameter estimates of Table 2 it appears that we cannot reject the restriction that there are 3 different types of countries. ${ }^{10}$ The second column of Table 4 shows estimation results if we assume $\beta_{2}$ to be a random coefficient with a discrete distribution that has two points of support $\beta_{2 a}$ and $\beta_{2 b}$ and mass points $p$ and $1-p .{ }^{11}$ The estimation results indicate that $\widehat{\beta}_{2 a}=-0.20$ with a probability-mass of $88 \%$ and $\widehat{\beta}_{2 b}=-0.11$, with a probability-mass of $12 \%$. Again, from a LR-test it appears that we cannot reject the reduction of the 12 country-specific $\beta_{2}$ 's to $2 \beta_{2}$ 's, that are both significantly smaller than zero. All in all, although there is some parameter heterogeneity it is clear that the unemployment rate has a significant negative effect on the non-fatal accident rate.

\section{Conclusions}

In this paper we develop a theoretical model to explain cyclical fluctuations in workplace accidents. We distinguish between two possible explanations, workplace conditions and reporting behavior. The 'workplace conditions' explanation

\footnotetext{
${ }^{10}$ We investigated whether the country-specific coefficients $\beta_{2}$ are correlated with the countryspecific unemployment benefit replacement rates, but found this not to be the case.

${ }^{11}$ The parameters of this mixing distribution are estimated using maximum likelihood.
} 
predicts that the level of unemployment is negatively related to workplace accidents because effort is negatively related to unemployment. Furthermore, it predicts that working hours are positively related to workplace accidents because working longer increases the probability of an accidents to occur. Also, the change in employment is positively related to workplace accidents since an increase in employment coincides with a lot of new hirings while a decrease in employment is related to few new hirings. The 'reporting' explanation predicts that both the level and the change in unemployment are negatively related to workplace accidents. Another distinction between the two alternative explanations has to do with fatal accidents. If cycles in workplace conditions drive the cycles in workplace accidents this should also be the case for fatal accidents. If reporting behavior of workers is relevant then fatal accidents should not be affected by the unemployment rate or changes in the unemployment rate, because with fatal accidents there is no reporting decision.

In our empirical analysis based on information from OECD countries we find that workplace accidents are inversely related to both the level of unemployment and the change in unemployment, while working hours and changes in employment do not affect accidents rates. Furthermore, fatal accident rates do not seem to be related to labor market conditions. From all this we conclude that the cyclical fluctuations in workplace accidents have to do with reporting behavior of workers. If unemployment is high or increasing workers are less likely to report about workplace accidents than they are in situations of low or decreasing unemployment. We find no evidence that working conditions deteriorate in cyclical upturns. Workplace safety does not change over the cycle. 


\section{References}

Arai, Mahmood and Peter Skogman Thoursie (2001) Incentives and selection in cyclical absenteeism, Working Paper, Stockholm University.

Askildsen, Jan Erik, Espen Bratberg and Øivind Anti Nilsen (2002) Unemployment, labor force composition and sickness absence; a panel data study, Working Paper, University of Bergen.

Barmby, Tim A., John G. Sessions and John G. Treble (1994) Absenteeism, efficiency wages and shirking, Scandinavian Journal of Economics, 96 (4), 561-566.

Brown, Sarah and John G. Sessions (1996) The economics of absence: theory and evidence, Journal of Economic Surveys, 10, 23-53.

Fairris, David (1998) Institutional change in shopfloor governance and the trajectory of postwar injury rates in U.S. manufacturing, 1946-1970, Industrial and Labor Relations Review, 51, 187-203.

Guadalupe, Maria (2002) The hidden costs of fixed term contracts: the impact on work accidents, Centre for Economic Performance, London School of Economics, mimeo.

Hokkanen, Jyry (1998) Interpreting budget deficits and productivity fluctuations, Economic Studies 42, Dissertation Uppsala University.

Johansson, Per and Mårten Palme (1996) Do economic incentives affect work absence? Empirical evidence using Swedish micro data, Journal of Public Economics, 59, 195-218.

Johansson, Per and Mårten Palme (2002) Assessing the effect of public policy on worker absenteeism, Journal of Human Resources, 37, 381-409.

Kniesner, Thomas J. and John D. Leeth (1989) Separating the reporting effects from the injury rate effects of workers' compensation insurance: a hedonic simulation, Industrial and Labor Relations Review, 42, 280-293.

Kossoris, Max (1938) Industrial injuries and the business cycle, Monthly Labor Review, March, 579-594.

Leigh, J. Paul (1985) The effects of unemployment and the business cycle on absenteeism, Journal of Economics and Business, 37, 159-170. 
Meyer, Bruce D., W. Kip Viscusi, David L. Durbin (1995) Workers' compensation and injury duration: evidence from a natural experiment, American Economic Review, 85, 322-340.

Mortensen, D. and C. Pissarides (1999) New developments in models of search in the labor market, In Ashenfelter, O. and D. Card (Eds.), Handbook of Labor Economics.

Nickell, Stephen J., Luca Nunciata, Wolfgang Ochel and Glenda Quintini (2001) The Beveridge curve, unemployment and wage in the OECD, CEP Discussion Paper 502, London School of Economics.

Ruhm, Christopher J. (2000) Are recessions good for your health?, Quarterly Journal of Economics, May, 617-650.

Ruhm, Christopher J. (2001) Economic expansions are unhealthy, Working Paper, University of North Carolina.

Shea, John (1990) Accidents rates, labor effort, and the business cycle, SSRI Working Paper 9028, University of Wisconsin, Madison.

Schuster, Michael and Susan Rhodes (1985) The impact of overtime work on industrial accident rates, Industrial Relations, 24, 234-46. 


\section{Appendix 1: Information about the data}

The thirteenth International Conference of Labor Statisticians (Geneva, 1992) defined work accidents as accidents occurring at or in the course of work which may result in death, personal injury or disease. International comparisons of information about workplace accidents are difficult because sources of data, reporting procedures and coverage of the data may differ between countries. Coverage may be limited to certain types of workers or injuries giving rise to more than a certain number of days of absence from work. Table A1 describes some general characteristics of the information on workplace accidents.

Table A1 Information about workplace accidents in country statistics $^{a}$ )

$\begin{array}{lcccc} & \begin{array}{c}\text { Source } \\ \text { \& subject }\end{array} & \begin{array}{c}\text { Minimum } \\ \text { period (days) }\end{array} & \begin{array}{c}\text { Commuting } \\ \text { accidents }\end{array} & \begin{array}{c}\text { Breaks } \\ \text { in series }\end{array} \\ \text { 1. Austria } & \text { FA }-81 & 0 & \text { yes } & 1985-86 \\ \text { 2. Belgium } & \text { FA }-82 & 0 & \text { yes } & - \\ \text { 3. Canada } & \text { FA }-82 & 1 & \text { no } & - \\ \text { 4. Denmark } & \text { FF }-82 & 1 & \text { no } & 1982-83 \\ \text { 5. Finland } & \text { FA }-81 & 3 & \text { no } & - \\ \text { 6. France } & \text { FA }-82 & 1 & \text { no } & - \\ \text { 7. Germany } & \text { FA }-82 & 3 & \text { no } & 1990-91 \\ \text { 8. Ireland } & \text { FF }-81 & 4 & \text { no } & 1992-93 \\ \text { 9. Italy } & \text { FA }-82 & 3 & \text { yes } & 1989-90 \\ \text { 10. Luxembourg } & \text { FA }-82 & 0 & \text { no } & - \\ \text { 11. Netherlands } & \text { FA }-81 & 0 & \text { no } & - \\ \text { 12. Portugal } & \text { FA }-81 & 0 & \text { no } & - \\ \text { 13. Spain } & \text { FA }-81 & 1 & \text { no } & - \\ \text { 14. Sweden } & \text { FA }-81 & 1 & \text { no } & 1990-91 \\ \text { 15. Switzerland } & \text { FA }-82 & 1 & \text { no } & - \\ \text { 16. UK } & \text { FF }-81 & 4 & \text { no } & 1989-90 \\ \text { 17. US } & \text { DA }-81 & 1 & \text { no } & -\end{array}$

a) ILO classification. Source: DA = labor related establishment survey, FA = insurance records, FF = labor inspectorate records. Subject: $81=$ reported, $82=$ compensated. Denmark 1978-90 source $=82$. Germany until 1991: West-Germany 
Table A2 gives the sources of information for the data.

\section{Table A2 Sources of $\operatorname{data}^{a)}$}

1. Austria

Non-fatal

Fatal

Unemployment Employment

accidents

2. Belgium

national accidents

3. Canada

national

ILO

ILO

GGDC

4. Denmark

ILO

ILO

ILO

ILO

5. Finland

ILO, national

ILO

ILO

GGDC

ILO

ILO

GGDC

6. France

ILO

ILO

ILO

ILO

7. Germany

ILO, national

ILO, national

ILO

ILO

8. Ireland

ILO, national

ILO, national

national

GGDC

9. Italy

ILO

ILO

national

ILO

ILO

ILO

ILO

ILO

10. Luxembourg

national

national

ILO

ILO

11. Netherlands

ILO, national

ILO

ILO

GGDC

12. Portugal

ILO

ILO

ILO

GGDC

13. Spain

ILO

ILO

ILO

GGDC

14. Sweden

ILO, national

ILO, national

ILO

ILO

15. Switzerland

ILO

ILO

ILO

ILO

16. UK

ILO

ILO

ILO

ILO

17 .US

ILO

ILO

ILO

ILO

a) ILO: Bureau of Statistics (LABORSTA)

National: various national statistics

GGDC: University of Groningen and The Conference Board, Growth \& Development Centre Total Economy Database, 2002, http://www.eco.rug.nl/ggdc

The information about hours actually worked per employee is from the GGDC. Since this dataset does not contain the information about working hours from Luxembourg we have replaced this series with information about Belgium. 


\section{Appendix 2: Proof of results}

We begin this appendix with some preliminary results that will be used later on. In particular, we introduce a class of differential equations which we do not solve as initial value problems. Instead we impose a condition on the steady state behavior of the solution to the differential equation.

Lemma 4 Let $g($.$) be a real valued function of t \in \Re$ with $|g()|<$.$M for some$ $M>0$. Consider the differential equation

$$
\psi h(t)=g(t)+\dot{h}(t)
$$

with the following boundary condition: if for some $T>0$ it is the case that $g(t)=\bar{g}$ for all $t \geq T$ then $h(t)=\frac{\bar{g}}{\psi}$ for all $t \geq T$.

The solution to this differential equation is

$$
h(t)=\frac{1}{\psi} \bar{g}^{\psi}(t)
$$

where

$$
\bar{g}^{\psi}(t) \equiv \psi \int_{t}^{+\infty} e^{-\psi(s-t)} g(s) d s
$$

\section{Proof}

To solve differential equation (8) we solve the homogenous part of the equation first, that is

$$
\psi h(t)=\dot{h}(t)
$$

The solution to this equation is clearly

$$
h(t)=c e^{\psi t}
$$

In order to solve the original equation, we write the constant $c$ as a function of $t$. So we try as a solution $h(t)=c(t) e^{\psi t}$. Substituting this into equation (8), we get

$$
\psi c(t) e^{\psi t}=g(t)+c^{\prime}(t) e^{\psi t}+\psi c(t) e^{\psi t}
$$

or equivalently

$$
c^{\prime}(t)=-e^{-\psi t} g(t)
$$


So we can solve $c(t)$ as

$$
c(t)=\int_{t}^{+\infty} e^{-\psi s} g(s) d s+c_{0}
$$

for some constant $c_{0}$. Substituting this into $h(t)=c(t) e^{\psi t}$ we get

$$
h(t)=\left(\int_{t}^{+\infty} e^{-\psi s} g(s) d s+c_{0}\right) e^{\psi t}
$$

Using the boundary condition that $g(t)=\bar{g}$ for all $t$ must imply $h(t)=\frac{\bar{g}}{\psi}$ yields $c_{0}=0$. Hence we find as solution to equation (8)

$$
\begin{aligned}
h(t) & =\int_{t}^{+\infty} e^{-\psi(s-t)} g(s) d s \\
& =\frac{1}{\psi} \bar{g}^{\psi}(t)
\end{aligned}
$$

Q.E.D.

Lemma 5 Let $\bar{g}^{\delta}(t)$ denote

$$
\bar{g}^{\delta}(t) \equiv \delta \int_{t}^{+\infty} e^{-\delta(s-t)} g(s) d s
$$

for $\delta>0$ then

$$
\overline{\bar{g}}^{\delta}(t) \equiv \psi \int_{t}^{+\infty} e^{-\psi(s-t)} \bar{g}^{\delta}(s) d s=\frac{\bar{g}^{\delta}(t)-\frac{\delta}{\psi} \bar{g}^{\psi}(t)}{1-\frac{\delta}{\psi}}
$$

for $\psi>0$.

\section{Proof}

Using integration by parts we get

$$
\begin{aligned}
& \overline{\bar{g}}^{\delta} \psi(t)=\delta\left\{\begin{array}{c}
{\left[-e^{-\psi(s-t)} \int_{s}^{+\infty} e^{-\delta(\tau-s)} g(\tau) d \tau\right]_{t}^{+\infty}+} \\
+\int_{t}^{+\infty} e^{-\psi(s-t)}\left[-g(s)+\delta \int_{s}^{+\infty} e^{-\delta(\tau-s)} g(\tau) d \tau\right] d s
\end{array}\right\} \\
& =\left[\bar{g}^{\delta}(t)\right]-\delta \int_{t}^{+\infty} e^{-\psi(s-t)} g(s) d s+\delta \int_{t}^{+\infty} e^{-\psi(s-t)} \delta \int_{s}^{+\infty} e^{-\delta(\tau-s)} g(\tau) d \tau d s \\
& =\bar{g}^{\delta}(t)-\frac{\delta}{\psi} \bar{g}^{\psi}(t)+\frac{\delta}{\psi} \overline{\bar{g}}^{\delta}(t)
\end{aligned}
$$

and hence the result in equation (9) follows. Q.E.D. 
Lemma 6 The solution to differential equations (1) and (2), where $V_{u}(t)$ is some function of time $t$ satisfying the conditions in the text, can be characterized as follows

$$
\begin{aligned}
V_{A}(t)= & \frac{w+\phi \int_{0}^{+\infty}[-\alpha+\gamma(\alpha)] f(\alpha) d \alpha}{\rho+\delta_{A}}+\frac{\delta_{A}}{\rho+\delta_{A}} \bar{V}_{u}^{\rho+\delta_{A}}(t) \\
V_{E}(t)-V_{A}(t)= & \frac{-\phi \int_{0}^{\bar{\alpha}} \gamma(\alpha) f(\alpha) d \alpha+\left(\delta_{A}-\delta_{E}\right) \frac{w+\phi \int_{0}^{+\infty}[-\alpha+\gamma(\alpha)] f(\alpha) d \alpha}{\rho+\delta_{A}}}{\rho+\delta_{E}+\phi(1-F(\bar{\alpha}))}+ \\
& \left(\delta_{A}-\delta_{E}\right) \frac{\bar{g}^{\rho+\delta_{E}+\phi(1-F(\bar{\alpha}))}(t)}{\rho+\delta_{E}+\phi(1-F(\bar{\alpha}))}
\end{aligned}
$$

where $\bar{\alpha}$ is determined by $\gamma(\bar{\alpha})=V_{E}(t)-V_{A}(t)$ and the function $g($.$) is defined$ as

$$
g(t) \equiv \frac{\delta_{A}}{\rho+\delta_{A}} \bar{V}_{u}^{\rho+\delta_{A}}(t)-V_{u}(t)
$$

\section{Proof}

Consider first the equation for $V_{A}(t)$. Writing equation (2) as

$$
\left(\rho+\delta_{A}\right) V_{A}(t)=w+\phi \int_{0}^{+\infty}[-\alpha+\gamma(\alpha)] f(\alpha) d \alpha+\delta_{A} V_{u}(t)+\dot{V}_{A}(t)
$$

we see it is a differential equation of the form (8). Hence lemma 4 implies that the solution can be written as equation (10).

Now turn to the difference $V_{E}(t)-V_{A}(t)$. Writing equation $(1)$ as

$$
\begin{aligned}
\left(\rho+\delta_{E}\right) V_{E}(t)= & w-\phi \int_{0}^{+\infty} \alpha f(\alpha) d \alpha+\phi \int_{\bar{\alpha}}^{+\infty}\left[\gamma(\alpha)-\left(V_{E}(t)-V_{A}(t)\right)\right] f(\alpha) d \alpha+ \\
& \delta_{E} V_{u}(t)+\dot{V}_{E}(t)
\end{aligned}
$$

where $\bar{\alpha}$ is the smallest value of $\alpha$ for which

$$
\max \left\{\gamma(\alpha)-\left(V_{E}(t)-V_{A}(t)\right), 0\right\}=\gamma(\alpha)-\left(V_{E}(t)-V_{A}(t)\right)
$$

(recall that $\gamma($.$) is nondecreasing in \alpha$ ). In other words, by continuity of $\gamma($.$) , we$ have that

$$
\gamma(\bar{\alpha})=V_{E}(t)-V_{A}(t)
$$

Subtracting from (14) equation (13), we get

$$
\begin{aligned}
& \left(\rho+\delta_{E}\right)\left[V_{E}(t)-V_{A}(t)\right]+\left(\delta_{E}-\delta_{A}\right) V_{A}(t) \\
= & -\phi \int_{0}^{\bar{\alpha}} \gamma(\alpha) f(\alpha) d \alpha-\phi\left[V_{E}(t)-V_{A}(t)\right](1-F(\bar{\alpha})) \\
& -\left(\delta_{A}-\delta_{E}\right) V_{u}(t)+\left[\dot{V}_{E}(t)-\dot{V}_{A}(t)\right]
\end{aligned}
$$


Defining $\Delta_{E A}(t) \equiv V_{E}(t)-V_{A}(t)$ and substituting into this equation the solution for $V_{A}(t)$ in equation (10) we find

$$
\begin{aligned}
\left(\rho+\delta_{E}+\phi(1-F(\bar{\alpha}))\right) \Delta_{E A}(t)= & -\phi \int_{0}^{\bar{\alpha}} \gamma(\alpha) f(\alpha) d \alpha+ \\
& \left(\delta_{A}-\delta_{E}\right) \frac{w+\phi \int_{0}^{+\infty}[-\alpha+\gamma(\alpha)] f(\alpha) d \alpha}{\rho+\delta_{A}}+ \\
& \left(\delta_{A}-\delta_{E}\right)\left(\frac{\delta_{A}}{\rho+\delta_{A}} \bar{V}^{\rho+\delta_{A}}(t)-V_{u}(t)\right)+\dot{\Delta}_{E A}(t)
\end{aligned}
$$

First, note that $\bar{\alpha}$ is a function of $\Delta_{E A}(t)$, but due to an Envelope Theorem type of argument we can ignore this indirect effect on $V_{E}$ via $\bar{\alpha}$. Therefore we can also ignore the effect of a change in $\bar{\alpha}$ on $\Delta_{E A}(t)$. Second, note that this differential equation for $\Delta_{E A}(t)$ has the same form as equation (8). Applying the solution in lemma 4 gives us equation (11) above. Q.E.D.

\section{Proof of proposition 1}

The number of accidents reported at time $t$ depends negatively on $\Delta_{E A}(t)$ because $\gamma(\bar{\alpha})=\Delta_{E A}$ and the fraction of accidents reported equals $(1-F(\bar{\alpha}))$. Hence showing that under time path $V_{u}(t)+\varepsilon$ with $\varepsilon>0$ more accidents are reported than under time path $V_{u}(t)$ boils down to showing that $\Delta_{E A}(t)$ is lower with $V_{u}(t)+\varepsilon$ than with $V_{u}(t)$. Looking at the solution in equation (11), a sufficient condition for this is that $g(t)$ as defined in equation (12) is always lower under path $V_{u}(t)+\varepsilon$ than under path $V_{u}(t)$. Let $g_{\varepsilon}(t)$ denote the path for $g(t)$ under $V_{u}(t)+\varepsilon$ while $g_{0}(t)$ denotes the path under $V_{u}(t)$. Then we want to prove that $g_{0}(t)-g_{\varepsilon}(t)$ is positive for all $t$. It is routine to verify that

$$
\begin{aligned}
g_{0}(t)-g_{\varepsilon}(t)= & {\left[\frac{\delta_{A}}{\rho+\delta_{A}} \bar{V}_{u}^{\rho+\delta_{A}}(t)-V_{u}(t)\right] } \\
& -\left[\frac{\delta_{A}}{\rho+\delta_{A}}\left(\bar{V}_{u}^{\rho+\delta_{A}}(t)+\varepsilon\right)-\left(V_{u}(t)+\varepsilon\right)\right] \\
= & \varepsilon \frac{\rho}{\rho+\delta_{A}}>0
\end{aligned}
$$

Q.E.D.

\section{Proof of proposition 2}

To simplify notation later on, define the function $\varepsilon(t)$ as the difference between the two time paths, that is

$$
\varepsilon(t) \equiv V_{u 2}(t)-V_{u 1}(t)
$$


Then the conditions in the proposition can be written as

$$
\begin{aligned}
\varepsilon(0) & =0 \\
\bar{\varepsilon}^{\rho+\delta_{A}}(0) & =0 \\
\varepsilon^{\prime}(0) & <0
\end{aligned}
$$

and there exists $T>0$ such that

$$
\varepsilon(t)=0 \text { for all } t \geq T
$$

On the basis of this, we have to show that $\Delta_{A E}(0)$ is bigger under time path $V_{u 2}$ than under $V_{u 1}$ (because that implies that more accidents are reported at time $t=0$ under $V_{u 1}$ than under $V_{u 2}$ ). Similar to the proof of proposition 1, we need to consider the difference between the function $g($.$) (as defined in (12)) under$ time path $V_{u 2}$, denoted by $g_{\varepsilon}(t)$, and under time path $V_{u 1}$, denoted $g_{0}(t)$. It is routine to verify that this difference can be written as

$$
\begin{aligned}
g_{\varepsilon}(t)-g_{0}(t)= & {\left[\frac{\delta_{A}}{\rho+\delta_{A}}\left(\bar{V}_{u 1}^{\rho+\delta_{A}}(t)+\bar{\varepsilon}^{\rho+\delta_{A}}(t)\right)-\left(V_{u 1}(t)+\varepsilon(t)\right)\right] } \\
& -\left[\frac{\delta_{A}}{\rho+\delta_{A}} \bar{V}_{u 1}^{\rho+\delta_{A}}(t)-V_{u 1}(t)\right] \\
= & \frac{\delta_{A}}{\rho+\delta_{A}} \bar{\varepsilon}^{\rho+\delta_{A}}(t)-\varepsilon(t)
\end{aligned}
$$

It follows that $\Delta_{A E}(0)$ is bigger under time path $V_{u 2}$ than under $V_{u 1}$ if and only if

$$
\left(\rho+\delta_{E}+\phi(1-F(\bar{\alpha}))\right) \int_{0}^{+\infty} e^{-\left(\rho+\delta_{E}+\phi(1-F(\bar{\alpha}))\right) t}\left[\frac{\delta_{A}}{\rho+\delta_{A}} \bar{\varepsilon}^{\rho+\delta_{A}}(t)-\varepsilon(t)\right] d t>0
$$

Using lemma 5 above, we find that

$$
\begin{aligned}
& \frac{\delta_{A}}{\rho+\delta_{A}} \overline{\bar{\varepsilon}}^{\rho+\delta_{A}}{ }^{\rho+\delta_{E}+\phi(1-F(\bar{\alpha}))}(0) \\
= & \frac{\delta_{A}}{\rho+\delta_{A}}\left(\rho+\delta_{E}+\phi(1-F(\bar{\alpha}))\right) \int_{0}^{+\infty} e^{-\left(\rho+\delta_{E}+\phi(1-F(\bar{\alpha}))\right) t} \bar{\varepsilon}^{\rho+\delta_{A}}(t) d t \\
= & \frac{\delta_{A}}{\rho+\delta_{A}} \frac{\bar{\varepsilon}^{\rho+\delta_{A}}(0)-\frac{\rho+\delta_{A}}{\rho+\delta_{E}+\phi(1-F(\bar{\alpha}))} \bar{\varepsilon}^{\rho+\delta_{E}+\phi(1-F(\bar{\alpha}))}(0)}{1-\frac{\rho+\delta_{A}}{\rho+\delta_{E}+\phi(1-F(\bar{\alpha}))}}
\end{aligned}
$$

Using the condition above that $\bar{\varepsilon}^{\rho+\delta_{A}}(0)=0$, we can rewrite inequality (15) as

$$
-\frac{\delta_{A}}{\rho+\delta_{A}} \frac{\frac{\rho+\delta_{A}}{\rho+\delta_{E}+\phi(1-F(\bar{\alpha}))} \bar{\varepsilon}^{\rho+\delta_{E}+\phi(1-F(\bar{\alpha}))}(0)}{1-\frac{\rho+\delta_{A}}{\rho+\delta_{E}+\phi(1-F(\bar{\alpha}))}}-\bar{\varepsilon}^{\rho+\delta_{E}+\phi(1-F(\bar{\alpha}))}(0)>0
$$


or equivalently

$$
\bar{\varepsilon}^{\rho+\delta_{E}+\phi(1-F(\bar{\alpha}))}(0)\left[-\frac{\delta_{A}}{\rho+\delta_{A}} \frac{\frac{\rho+\delta_{A}}{\rho+\delta_{E}+\phi(1-F(\bar{\alpha}))}}{1-\frac{\rho+\delta_{A}}{\rho+\delta_{E}+\phi(1-F(\bar{\alpha}))}}-1\right]>0
$$

which can be written as

$$
\frac{\delta_{E}+\phi(1-F(\bar{\alpha}))}{\delta_{A}}\left[\bar{\varepsilon}^{\rho+\delta_{E}+\phi(1-F(\bar{\alpha}))}(0) \frac{\delta_{A}}{\left(\delta_{A}-\delta_{E}\right)-\phi(1-F(\bar{\alpha}))}\right]>0
$$

Clearly the fraction $\frac{\delta_{E}+\phi(1-F(\bar{\alpha}))}{\delta_{A}}$ is strictly positive. So the remainder of this proof shows that the term between square brackets is positive.

Return to the expression for $\frac{\delta_{A}}{\rho+\delta_{A}} \times{\overline{\bar{\varepsilon}^{\rho+\delta_{A}}}}^{\rho+\delta_{E}+\phi(1-F(\bar{\alpha}))}(0)$ in equation (16). The expression $\overline{\bar{\varepsilon}}^{\rho+\delta_{A}} \rho+\delta_{E}+\phi(1-F(\bar{\alpha}))(0)$ is the weighted average of the future values of $\bar{\varepsilon}^{\rho+\delta_{A}}$ as of time 0 (where the weights follow an exponential distribution with parameter $\left.\rho+\delta_{E}+\phi(1-F(\bar{\alpha}))\right)$. The following lemma shows that $\bar{\varepsilon}^{\rho+\delta_{A}}(t)$ is nonnegative for all $t \geq 0$ and strictly positive for some $t \geq 0$. Hence the weighted average of $\bar{\varepsilon}^{\rho+\delta_{A}}$ as of time 0 is strictly positive as well, that is $\overline{\bar{\varepsilon}}^{\rho+\delta_{A}} \rho+\delta_{E}+\phi(1-F(\bar{\alpha}))(0)>0$, which we use below.

Lemma 7 It is the case that

$$
\begin{aligned}
& \bar{\varepsilon}^{\rho+\delta_{A}}(t) \geq 0 \text { for all } t \geq 0 \\
& \bar{\varepsilon}^{\rho+\delta_{A}}(t)>0 \text { for } t \in\langle 0, T\rangle
\end{aligned}
$$

Hence we find that

$$
\begin{aligned}
{\overline{\bar{\varepsilon}^{\rho+\delta_{A}}}}^{\rho+\delta_{E}+\phi(1-F(\bar{\alpha}))}(0) & =\left(\rho+\delta_{E}+\phi(1-F(\bar{\alpha}))\right) \int_{0}^{+\infty} e^{-\left(\rho+\delta_{E}+\phi(1-F(\bar{\alpha}))\right) t} \bar{\varepsilon}^{\rho+\delta_{A}}(t) 18 t \\
& >0
\end{aligned}
$$

\section{Proof of Lemma 7}

Consider figure 1 which shows a path for $\varepsilon(t)$ satisfying the conditions in the lemma above. Since $\varepsilon(t) \geq 0$ for all $t \geq t_{2}$ and $\varepsilon(t)>0$ for all $t \in\left\langle t_{2}, T\right\rangle$ it is clear that $\bar{\varepsilon}^{\rho+\delta_{A}}(t)>0$ for $t \in\left[t_{2}, T\right\rangle$. We need to prove that $\bar{\varepsilon}^{\rho+\delta_{A}}(t) \geq 0$ for $t \in\left\langle 0, t_{2}\right\rangle$. This we prove by contradiction. Suppose not, that is suppose that $\bar{\varepsilon}^{\rho+\delta_{A}}\left(t_{1}\right)<0$ for some $t_{1} \in\left\langle 0, t_{2}\right\rangle$ (see figure 1 ), then by continuity of $\bar{\varepsilon}^{\rho+\delta_{A}}(t)$ the intermediate value theorem implies that there exists $\bar{t} \in\left\langle t_{1}, t_{2}\right\rangle$ such 
that $\bar{\varepsilon}^{\rho+\delta_{A}}(\bar{t})=0$. We can now write $\bar{\varepsilon}^{\rho+\delta_{A}}(0)$ as

$$
\begin{aligned}
& \bar{\varepsilon}^{\rho+\delta_{A}}(0)=\left(\rho+\delta_{A}\right) \int_{0}^{\bar{t}} e^{-\left(\rho+\delta_{A}\right) t} \varepsilon(t) d t+\left(\rho+\delta_{A}\right) e^{-\left(\rho+\delta_{A}\right) \bar{t}} \int_{\bar{t}}^{+\infty} e^{-\left(\rho+\delta_{A}\right)(t-\bar{t})} \varepsilon(t) d t \\
& =\left(\rho+\delta_{A}\right) \int_{0}^{\bar{t}} e^{-\left(\rho+\delta_{A}\right) t} \varepsilon(t) d t+e^{-\left(\rho+\delta_{A}\right) \bar{t}_{\bar{\varepsilon}}^{\rho+\delta_{A}}}(\bar{t}) \\
& =\left(\rho+\delta_{A}\right) \int_{0}^{\bar{t}} e^{-\left(\rho+\delta_{A}\right) t} \varepsilon(t) d t
\end{aligned}
$$

because by definition of $\bar{t}$ we have $\bar{\varepsilon}^{\rho+\delta_{A}}(\bar{t})=0$. However, since $\varepsilon(t)<0$ for all $t \in\left\langle 0, t_{2}\right\rangle$ (see figure 1) these equations imply that $\bar{\varepsilon}^{\rho+\delta_{A}}(0)<0$ which contradicts our assumption on $\varepsilon(t)$ that $\bar{\varepsilon}^{\rho+\delta_{A}}(0)=0$. Hence, there cannot be a value $t_{1} \in\left\langle 0, t_{2}\right\rangle$ such that $\bar{\varepsilon}^{\rho+\delta_{A}}\left(t_{1}\right)<0$. Consequently, $\bar{\varepsilon}^{\rho+\delta_{A}}(t) \geq 0$ for $t \in\left\langle 0, t_{2}\right\rangle$, which we needed to prove.

Since ${\overline{\bar{\varepsilon}^{\rho+\delta_{A}}}}^{\rho+\delta_{E}+\phi(1-F(\bar{\alpha}))}(0)$ is the weighted average of a variable that is non-negative everywhere and strictly positive for some $t>0$

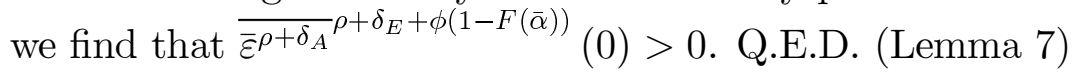

Using inequality (18) in (16) we find that

$$
-\frac{\delta_{A}}{\rho+\delta_{A}} \frac{\frac{\rho+\delta_{A}}{\rho+\delta_{E}+\phi(1-F(\bar{\alpha}))} \bar{\varepsilon}^{\rho+\delta_{E}+\phi(1-F(\bar{\alpha}))}(0)}{1-\frac{\rho+\delta_{A}}{\rho+\delta_{E}+\phi(1-F(\bar{\alpha}))}}>0
$$

It is routine to verify that this inequality can be rewritten as

$$
\bar{\varepsilon}^{\rho+\delta_{E}+\phi(1-F(\bar{\alpha}))}(0) \frac{\delta_{A}}{\left(\delta_{A}-\delta_{E}\right)-\phi(1-F(\bar{\alpha}))}>0
$$

This is exactly the square bracketed term in equation (17), which we have now proved to be positive. Q.E.D. (Proposition 2) 


\section{Tables and graphs}

Table 1 Stylized facts about workplace accidents and labor markets ${ }^{a}$ )

\begin{tabular}{lccccc} 
& $\mathrm{a}$ & $\mathrm{fa}$ & $\mathrm{u}$ & \multicolumn{2}{c}{ correlation coefficient } \\
& $(\%)$ & $(0.1 \%)$ & $(\%)$ & $\mathrm{a}-\mathrm{u}$ & fa-u \\
1. Austria & $6.8(20)$ & $0.08(25)$ & 4.4 & $-0.90^{*}$ & $-0.81^{*}$ \\
2. Belgium & $8.1(28)$ & $0.04(15)$ & 9.8 & $-0.94^{*}$ & 0.44 \\
3. Canada & $3.8(15)$ & $0.06(15)$ & 9.3 & -0.13 & -0.42 \\
4. Denmark & $1.6(27)$ & $0.03(22)$ & 8.1 & 0.14 & -0.28 \\
5. Finland & $4.0(23)$ & $0.04(23)$ & 7.8 & $-0.86^{*}$ & $-0.48^{*}$ \\
6. France & $4.0(30)$ & $0.07(30)$ & 8.0 & $-0.99^{*}$ & $-0.98^{*}$ \\
7. Germany & $6.2(30)$ & $0.08(30)$ & 5.6 & $-0.94^{*}$ & $-0.78^{*}$ \\
8. Ireland & $0.4(24)$ & $0.03(24)$ & 12.5 & $-0.60^{*}$ & 0.03 \\
9. Italy & $4.0(21)$ & $0.07(21)$ & 10.5 & $-0.60^{*}$ & $-0.67^{*}$ \\
10. Luxembourg & $9.6(29)$ & $0.11(29)$ & 1.7 & $-0.93^{*}$ & $-0.78^{*}$ \\
11. Netherlands & $1.6(23)$ & $0.01(14)$ & 6.7 & $-0.73^{*}$ & $-0.65^{*}$ \\
12. Portugal & $6.2(18)$ & $0.08(20)$ & 6.8 & -0.16 & $0.56^{*}$ \\
13. Spain & $5.0(20)$ & $0.10(20)$ & 18.9 & $-0.44^{*}$ & $-0.37^{*}$ \\
14. Sweden & $2.1(30)$ & $0.03(28)$ & 3.6 & $-0.36^{*}$ & -0.24 \\
15. Switzerland & $3.3(16)$ & $0.03(16)$ & 2.4 & $-0.88^{*}$ & $-0.83^{*}$ \\
16. UK & $0.7(14)$ & $0.01(19)$ & 8.0 & 0.31 & $0.49^{*}$ \\
17. US & $2.4(24)$ & $0.04(24)$ & 6.5 & 0.06 & -0.12
\end{tabular}

a) In the calculation of the correlations breaks in the series have been taken into account; ${ }^{*}$ indicates that the correlation is significantly different from zero at a $5 \%$ level. The numbers in parentheses refer to the number of observations on which the calculation is based. The averages for the unemployment rate are calculated for the same year as the averages for the non-fatal workplace accidents rate. 
Table 2 Estimation results (t- values in parentheses) $\left.{ }^{a}\right)$

\begin{tabular}{|c|c|c|c|c|}
\hline \multicolumn{5}{|c|}{ All (356 observations, 17 countries) } \\
\hline & \multicolumn{2}{|c|}{ non-fatal accidents } & \multicolumn{2}{|c|}{ fatal accidents } \\
\hline & $(1)$ & $(2)$ & $(3)$ & $(4)$ \\
\hline $\ln (u)$ & $-0.109(5.9)$ & $-0.164(8.7)$ & $-0.160(4.0)$ & $-0.092(1.6)$ \\
\hline country t.t. & no & yes & no & yes \\
\hline \multicolumn{5}{|c|}{ EU countries (301 observations, 14 countries) } \\
\hline & \multicolumn{2}{|c|}{ non-fatal accidents } & \multicolumn{2}{|c|}{ fatal accidents } \\
\hline & $(1)$ & $(2)$ & $(3)$ & $(4)$ \\
\hline $\ln (u)$ & $-0.092(4.0)$ & $-0.187(9.6)$ & $-0.082(1.7)$ & $-0.063(1.0)$ \\
\hline country t.t. & no & yes & no & yes \\
\hline
\end{tabular}

Balanced panel, 1980-96 (204 observations, 12 countries)

non-fatal accidents

(1)

(2) $\ln (u)$

$\ln (u)$

$\ln (h)$

$\ln (u)$

$\Delta \ln (u)$

$\ln (u)$

$\Delta \ln (u)$ $\Delta \ln (e)$ fatal accidents

(3) 
Table 3 Sensitivity analysis, country-specific coefficients of $\ln (u)$; balanced panel $1980-96^{a}$

$\begin{array}{lcc} & \begin{array}{c}\text { Non-fatal } \\ \text { accidents }\end{array} & \begin{array}{c}\text { Fatal } \\ \text { accidents }\end{array} \\ \text { Austria } & -0.153(3.3) & -0.561(4.1) \\ \text { Denmark } & -0.101(0.5) & -0.264(1.0) \\ \text { Finland } & -0.177(8.5) & -0.066(0.8) \\ \text { France } & -0.773(6.2) & -0.729(2.4) \\ \text { Germany } & -0.271(5.9) & -0.020(0.1) \\ \text { Ireland } & -0.146(1.7) & -1.810(5.4) \\ \text { Italy } & -0.113(0.3) & -0.341(0.8) \\ \text { Luxembourg } & -0.166(4.1) & -0.048(0.2) \\ \text { Portugal } & -0.367(6.9) & 0.673(3.7) \\ \text { Spain } & -0.648(9.7) & -0.269(1.3) \\ \text { Sweden } & -0.199(3.2) & -0.170(1.3) \\ \text { US } & -0.398(4.7) & 0.569(1.4)\end{array}$

a) t-statistics based on robust standard errors in parentheses

Table 4 Additional estimates for workplace accidents, coefficients of $\ln (\mathrm{u})$, balanced panel $1980-96^{a}$

\begin{tabular}{lccc} 
Group fixed effects & & \multicolumn{2}{c}{ Random effects } \\
Group 1 & $-0.172(6.3)$ & $\beta_{2 a}$ & $-0.199(8.6)$ \\
Group 2 & $-0.695(10.1)$ & $\beta_{2 b}$ & $-0.106(4.5)$ \\
Group 3 & $-0.337(8.2)$ & $p$ & $0.879(32.2)$
\end{tabular}

$\begin{array}{lll}\text { LR-test statistic } \quad 2.8 & 8.2\end{array}$

a) t-statistics based on robust standard errors in parentheses; The LR-test statistic compares estimation results with those in Table 3; critical $\chi_{0.05}^{2}$-value with 9 degrees of freedom $=16.9$

b) Group 1: Austria, Denmark, Finland, Ireland, Italy, Luxembourg, Sweden; group 2: France, Spain; group 3: Germany, Portugal, US 


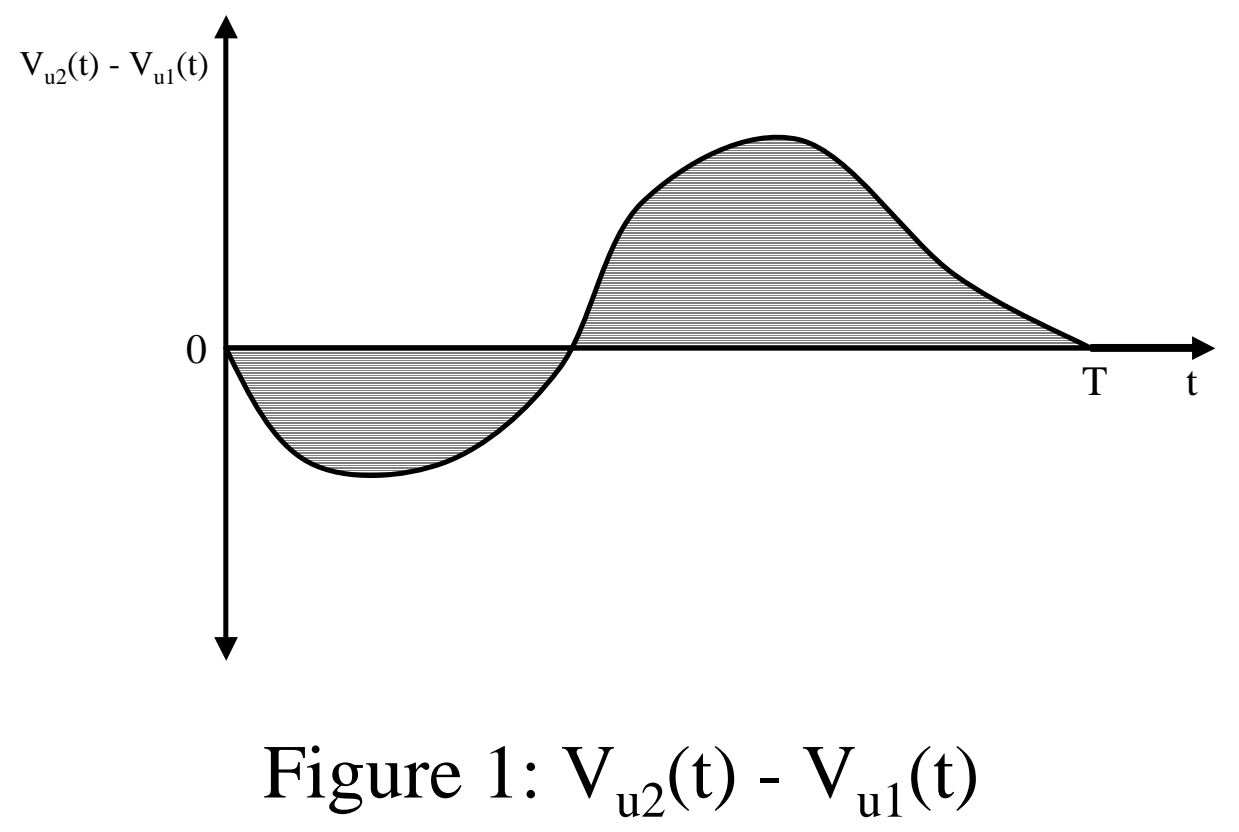


Figure 2 Unemployment and (non-fatal) workplace accidents in OECD countries; 1970-99
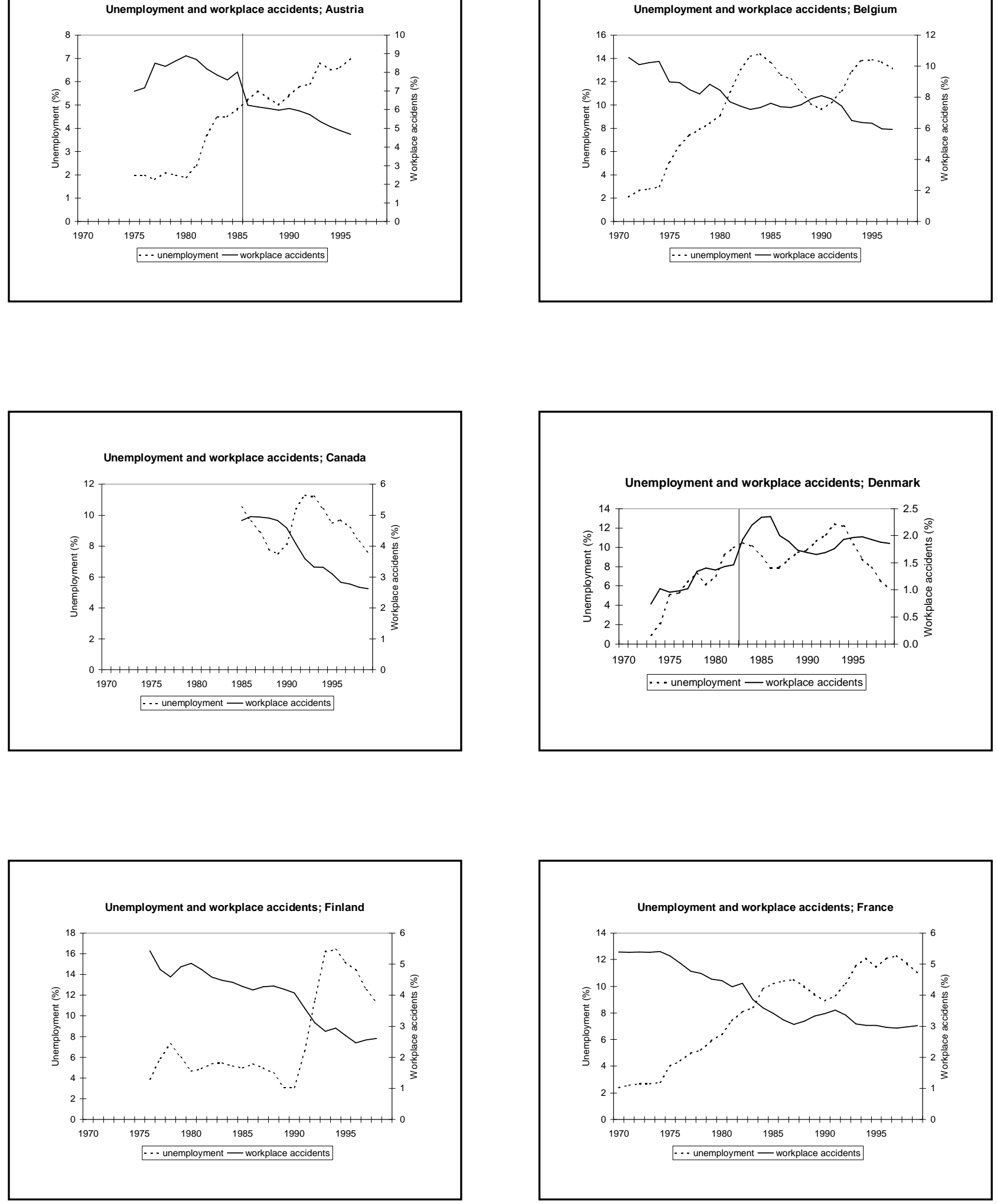
Figure 2 Unemployment and (non-fatal) workplace accidents in OECD countries; 1970-99
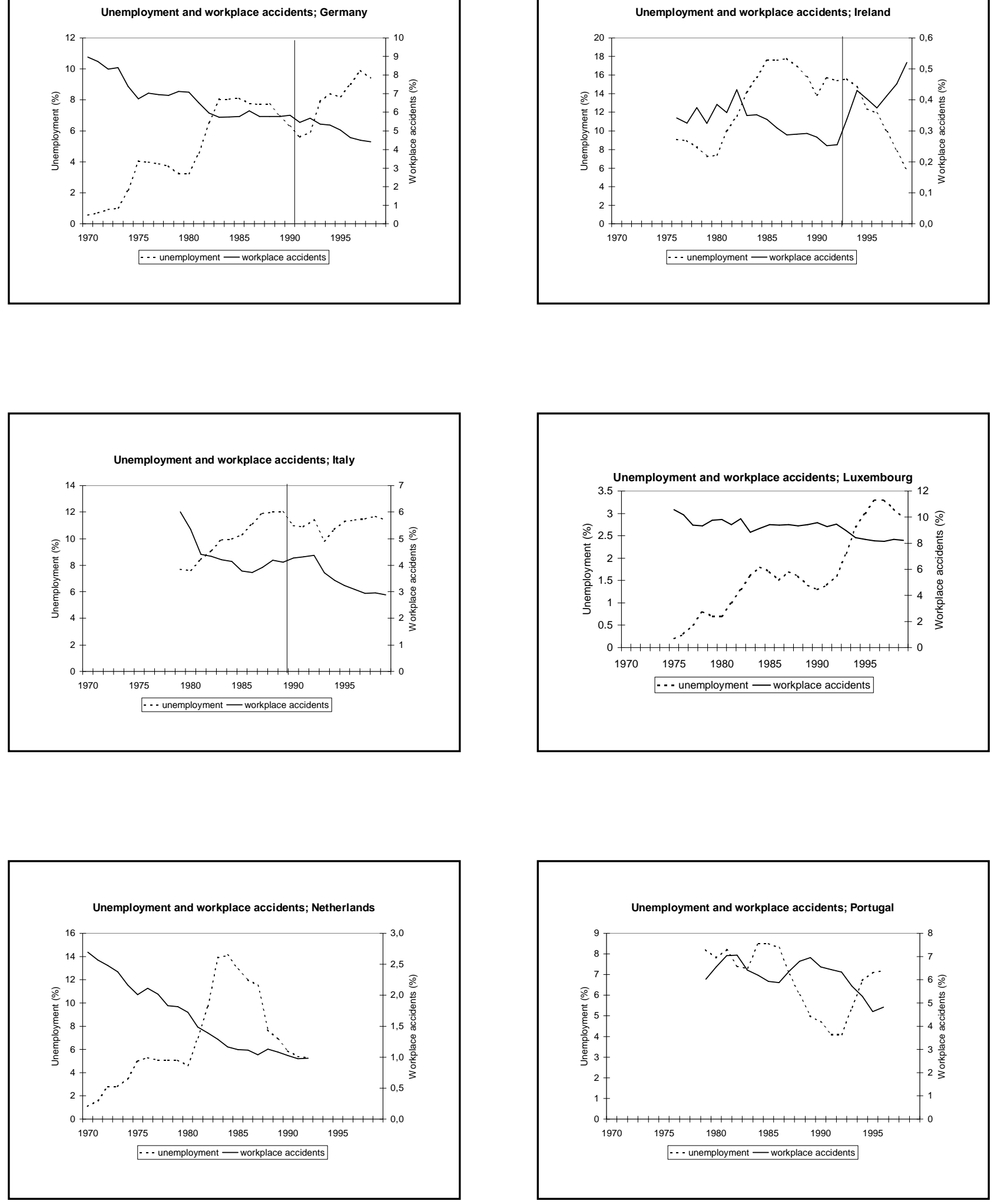
Figure 2 Unemployment and (non-fatal) workplace accidents in OECD countries; 1970-99
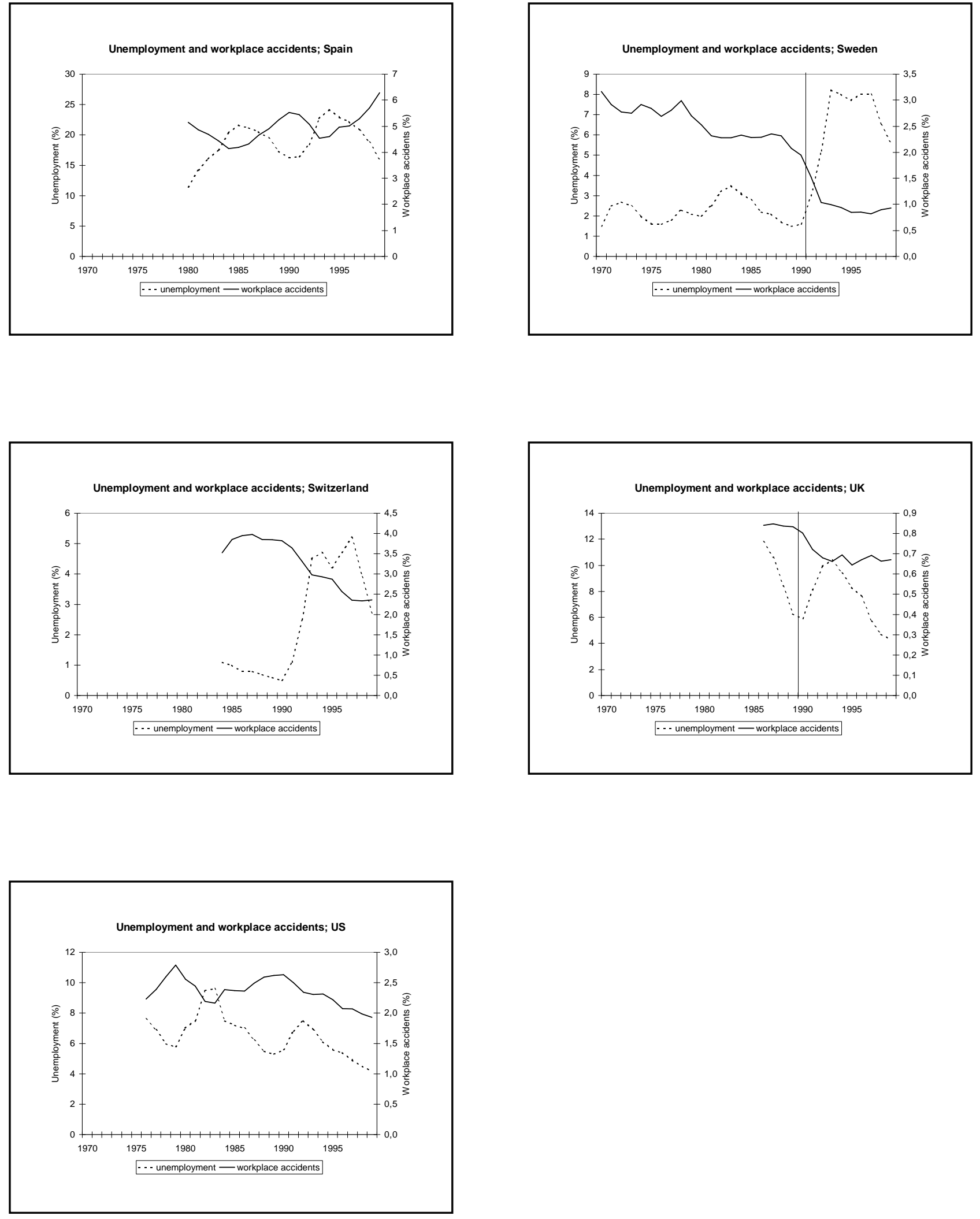


\section{IZA Discussion Papers}

\begin{tabular}{|c|c|c|c|c|}
\hline No. & Author(s) & Title & Area & Date \\
\hline 610 & A. Heitmueller & $\begin{array}{l}\text { Unemployment Benefits, Risk Aversion, and } \\
\text { Migration Incentives }\end{array}$ & 4 & $10 / 02$ \\
\hline 611 & G. Saint-Paul & $\begin{array}{l}\text { Some Thoughts on Macroeconomic Fluctuations } \\
\text { and the Timing of Labor Market Reform }\end{array}$ & 3 & $10 / 02$ \\
\hline 612 & $\begin{array}{l}\text { J. J. Dolado } \\
\text { M. Jansen } \\
\text { J. F. Jimeno }\end{array}$ & $\begin{array}{l}\text { A Matching Model of Crowding-Out and On-the- } \\
\text { Job Search (with an Application to Spain) }\end{array}$ & 2 & $10 / 02$ \\
\hline 613 & $\begin{array}{l}\text { P. Kuhn } \\
\text { M. Skuterud }\end{array}$ & $\begin{array}{l}\text { Internet Job Search and Unemployment } \\
\text { Durations }\end{array}$ & 5 & $10 / 02$ \\
\hline 614 & M. Pannenberg & $\begin{array}{l}\text { Long-Term Effects of Unpaid Overtime: } \\
\text { Evidence for West Germany }\end{array}$ & 1 & $10 / 02$ \\
\hline 615 & W. Koeniger & $\begin{array}{l}\text { The Dynamics of Market Insurance, Insurable } \\
\text { Assets, and Wealth Accumulation }\end{array}$ & 3 & $10 / 02$ \\
\hline 616 & $\begin{array}{l}\text { R. Hujer } \\
\text { U. Blien } \\
\text { M. Caliendo } \\
\text { C. Zeiss }\end{array}$ & $\begin{array}{l}\text { Macroeconometric Evaluation of Active Labour } \\
\text { Market Policies in Germany - A Dynamic Panel } \\
\text { Approach Using Regional Data }\end{array}$ & 6 & $10 / 02$ \\
\hline 617 & $\begin{array}{l}\text { L. Magee } \\
\text { M. R. Veall }\end{array}$ & $\begin{array}{l}\text { Allocating Awards Across Noncomparable } \\
\text { Categories }\end{array}$ & 1 & $10 / 02$ \\
\hline 618 & $\begin{array}{l}\text { A. L. Booth } \\
\text { M. Francesconi } \\
\text { G. Zoega }\end{array}$ & $\begin{array}{l}\text { Oligopsony, Institutions and the Efficiency of } \\
\text { General Training }\end{array}$ & 6 & $10 / 02$ \\
\hline 619 & $\begin{array}{l}\text { H. Antecol } \\
\text { D. A. Cobb-Clark }\end{array}$ & $\begin{array}{l}\text { The Changing Nature of Employment-Related } \\
\text { Sexual Harassment: Evidence from the U.S. } \\
\text { Federal Government (1978-1994) }\end{array}$ & 5 & $10 / 02$ \\
\hline 620 & D. A. Cobb-Clark & $\begin{array}{l}\text { Public Policy and the Labor Market Adjustment } \\
\text { of New Immigrants to Australia }\end{array}$ & 1 & $10 / 02$ \\
\hline 621 & G. Saint-Paul & On Market Forces and Human Evolution & 5 & $11 / 02$ \\
\hline 622 & $\begin{array}{l}\text { J. Hassler } \\
\text { J. V. Rodriguez Mora }\end{array}$ & Should UI Benefits Really Fall Over Time? & 3 & $11 / 02$ \\
\hline 623 & $\begin{array}{l}\text { A. R. Cardoso } \\
\text { P. Ferreira }\end{array}$ & $\begin{array}{l}\text { The Dynamics of Job Creation and Destruction } \\
\text { for University Graduates: Why a Rising } \\
\text { Unemployment Rate Can Be Misleading }\end{array}$ & 1 & $11 / 02$ \\
\hline 624 & $\begin{array}{l}\text { J. Wagner } \\
\text { R. Sternberg }\end{array}$ & $\begin{array}{l}\text { Personal and Regional Determinants of } \\
\text { Entrepreneurial Activities: Empirical Evidence } \\
\text { from the REM Germany }\end{array}$ & 1 & $11 / 02$ \\
\hline 625 & F. Galindo-Rueda & $\begin{array}{l}\text { Endogenous Wage and Capital Dispersion, On- } \\
\text { the-Job Search and the Matching Technology }\end{array}$ & 3 & $11 / 02$ \\
\hline 626 & A. Kunze & $\begin{array}{l}\text { Gender Differences in Entry Wages and Early } \\
\text { Career Wages }\end{array}$ & 5 & $11 / 02$ \\
\hline 627 & $\begin{array}{l}\text { J. Boone } \\
\text { J. C. van Ours }\end{array}$ & Cyclical Fluctuations in Workplace Accidents & 5 & $11 / 02$ \\
\hline
\end{tabular}

An updated list of IZA Discussion Papers is available on the center's homepage www.iza.org. 